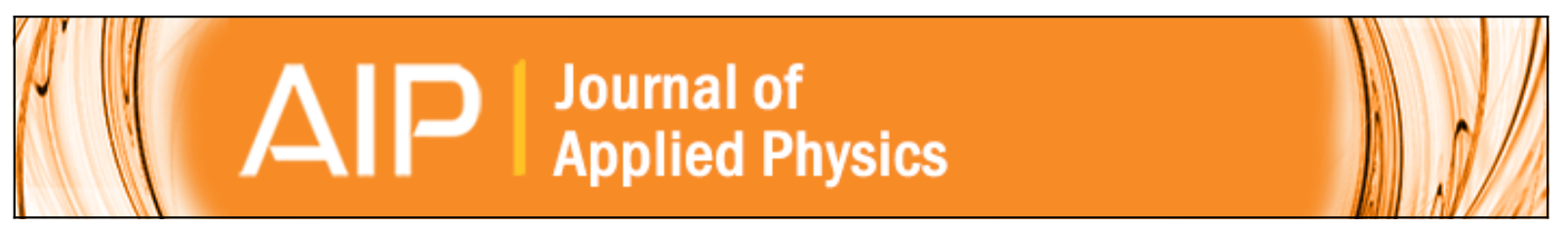

Electronic structure and optical properties of CdSxSe1-x solid solution nanostructures from X-ray absorption near edge structure, $X$-ray excited optical luminescence, and density functional theory investigations

M. W. Murphy, Y. M. Yiu, M. J. Ward, L. Liu, Y. Hu, J. A. Zapien, Yingkai Liu, and T. K. Sham

Citation: Journal of Applied Physics 116, 193709 (2014); doi: 10.1063/1.4902390

View online: http://dx.doi.org/10.1063/1.4902390

View Table of Contents: http://scitation.aip.org/content/aip/journal/jap/116/19?ver=pdfcov

Published by the AIP Publishing

Articles you may be interested in

Ca K-edge X-ray absorption fine structure in BaTiO3-CaTiO3 solid solutions

J. Appl. Phys. 113, 044106 (2013); 10.1063/1.4784226

In situ near-edge x-ray absorption fine structure spectroscopy investigation of the thermal defunctionalization of graphene oxide

J. Vac. Sci. Technol. B 30, 061206 (2012); 10.1116/1.4766325

Strong double excitation and open-shell features in the near-edge x-ray absorption fine structure spectroscopy of ferrocene and ferrocenium compounds

J. Chem. Phys. 131, 114313 (2009); 10.1063/1.3230101

Nanostructured CdS prepared on porous silicon substrate: Structure, electronic, and optical properties J. Appl. Phys. 91, 6038 (2002); 10.1063/1.1461888

Multichannel detection x-ray absorption near edge structures study on the structural characteristics of dendrimerstabilized CdS quantum dots

J. Appl. Phys. 90, 2755 (2001); 10.1063/1.1394899

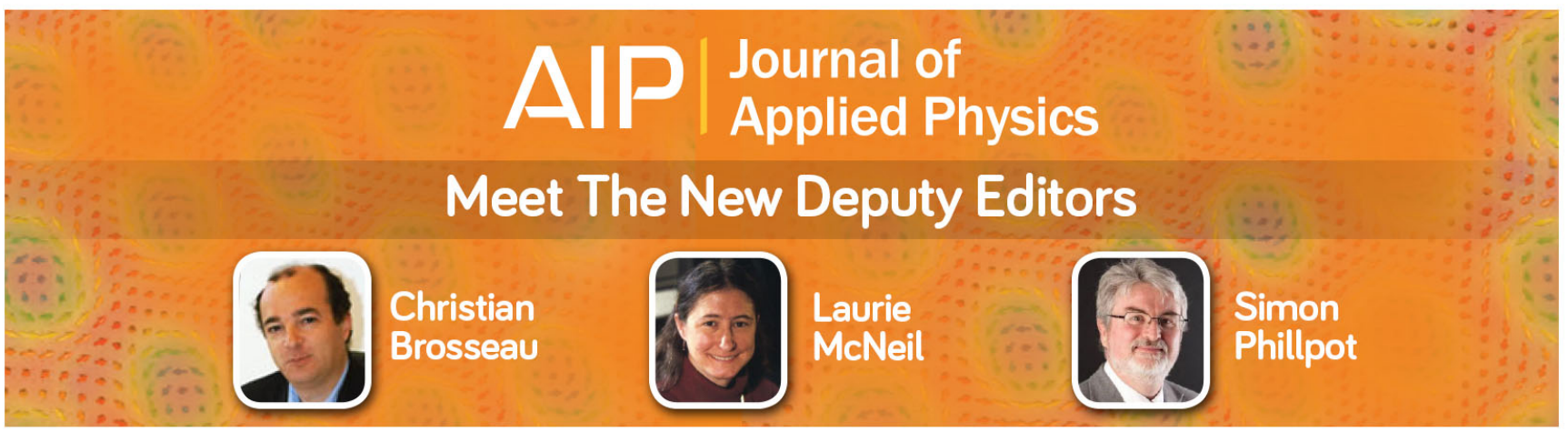




\title{
Electronic structure and optical properties of $\mathrm{CdS}_{\mathrm{x}} \mathrm{Se}_{1-\mathrm{x}}$ solid solution nanostructures from $X$-ray absorption near edge structure, $X$-ray excited optical luminescence, and density functional theory investigations
}

\author{
M. W. Murphy, ${ }^{1}$ Y. M. Yiu, ${ }^{2, a)}$ M. J. Ward,${ }^{3}$ L. Liu, ${ }^{4}$ Y. Hu, ${ }^{5}$ J. A. Zapien, ${ }^{6}$ Yingkai Liu, ${ }^{7}$ \\ and T. K. Sham ${ }^{2}$ \\ ${ }^{1}$ DESY (Deutsches Elektronen-Synchrotron), FS-PEX, Notkestrasse 85, 22607 Hamburg, Germany \\ ${ }^{2}$ Department of Chemistry, University of Western Ontario, London, ON N6A5B7, Canada \\ ${ }^{3}$ Cornell High Energy Synchrotron Source (CHESS), Cornell University, Ithaca, NY 14853, USA \\ ${ }^{4}$ Institute of Functional Nano and Soft Materials (FUNSOM) and Soochow University-Western University \\ Center for Synchrotron Radiation Research, Soochow University, Suzhou, Jiangsu, 215123, China \\ ${ }^{5}$ Canadian Light Source, University of Saskatchewan, Saskatoon, SK S7N2V3, Canada \\ ${ }^{6}$ Center Of Super-Diamond and Advanced Films (COSDAF) \& Department of Physics and Materials Science, \\ City University of Hong Kong, Hong Kong SAR, China \\ ${ }^{7}$ Institute of Physics and Electronic Information, Yunnan Normal University, Kunming, Yunnan, 650500, China
}

(Received 20 August 2014; accepted 11 November 2014; published online 21 November 2014)

The electronic structure and optical properties of a series of iso-electronic and iso-structural $\mathrm{CdS}_{\mathrm{x}} \mathrm{Se}_{1-\mathrm{x}}$ solid solution nanostructures have been investigated using X-ray absorption near edge structure, extended X-ray absorption fine structure, and X-ray excited optical luminescence at various absorption edges of $\mathrm{Cd}, \mathrm{S}$, and $\mathrm{Se}$. It is found that the system exhibits compositions, with variable local structure in-between that of $\mathrm{CdS}$ and $\mathrm{CdSe}$ accompanied by tunable optical band gap between that of $\mathrm{CdS}$ and CdSe. Theoretical calculation using density functional theory has been carried out to elucidate the observations. It is also found that luminescence induced by X-ray excitation shows new optical channels not observed previously with laser excitation. The implications of these observations are discussed. (C) 2014 AIP Publishing LLC.

[http://dx.doi.org/10.1063/1.4902390]

\section{INTRODUCTION}

Tailoring the physical properties of semiconducting nano-materials is critical for the development of new functional nano-scale devices. One goal is to have the ability to control the composition of semiconductor alloys and effectively tune the band-gap of a material for a specific function. As a result, various ternary alloys have recently attracted a great deal of attention for their ability to achieve a wide range of band-gaps, ${ }^{1-12}$ Additionally, nano-materials, such as nano-wires and nano-ribbons, offer greater versatility by providing a wider range of alloy composition and band-gap modulation which is unachievable using traditional epitaxial film materials due to lattice strain at the substrate interface. ${ }^{13}$

Ternary chalcogenide semiconductors, particularly cadmium sulpho-selenide $\left(\mathrm{CdS}_{\mathrm{x}} \mathrm{Se}_{1-\mathrm{x}}\right)$ alloys, have been intensely studied ${ }^{8,14-19}$ in part due to the remarkably broad range of stable stoichiometries that can be attained, owing to the small lattice mismatch among the constituent anions. ${ }^{14}$ CdS has a wurtzite (hexagonal) crystal structure with lattice parameters of $\mathrm{a}=4.16 \AA$ and $\mathrm{c}=6.76 \AA$, while CdSe, also a wurtzite, has lattice parameters of $\mathrm{a}=4.30 \AA$ and $\mathrm{c}=7.02 \AA .^{20}$ The lattice constants of the ternary $\mathrm{CdS}_{\mathrm{x}} \mathrm{Se}_{1-\mathrm{x}}$ alloys are known to closely follow Vegard's law ${ }^{21}$ and are nearly equal to the concentration weighted average of the lattice constants of the binary compounds. ${ }^{22}$ As a result of the

\footnotetext{
a) Author to whom correspondence should be addressed. Electronic mail: yyiu@uwo.ca
}

easily varied stoichiometries of crystalline wurtzite $\mathrm{CdS}_{\mathrm{x}} \mathrm{Se}_{1-\mathrm{x}}$ alloys, a continuous spectrum of direct band-gaps from $1.74 \mathrm{eV}(\mathrm{CdSe})$ to $2.43 \mathrm{eV}(\mathrm{CdS})(510-712 \mathrm{~nm})$ can be readily obtained. A variety of $\mathrm{CdS}_{\mathrm{x}} \mathrm{Se}_{1-\mathrm{x}}$ alloy nano-material morphologies have been synthesized, including nano-wires, nano-ribbons, nano-belts, nano-sheets, nano-crystals, and nano-particles with a variety of aspect ratios and stoichiometries. ${ }^{3,14,16,18,19}$ The diversity of electronic and spectral properties of $\mathrm{CdS}_{\mathrm{x}} \mathrm{Se}_{1-\mathrm{x}}$ alloy nanostructures has great potential applications in tunable optoelectronic devices, such as color engineered displays and lighting, ${ }^{19}$ multi-spectral detectors, ${ }^{13}$ full-spectrum solar cells, ${ }^{23}$ and broadly tunable nanolasers. ${ }^{8,15,24}$ Therefore, a detailed examination of the electronic structure and corresponding optical emission is essential to determine the full potential of these functional materials.

Using tunable X-rays from a synchrotron light source, the individual elements in the ternary $\mathrm{CdS}_{\mathrm{x}} \mathrm{Se}_{1-\mathrm{x}}$ matrix can be selectively measured by looking at the dipole transitions of the absorption edges specific to that element, e.g., X-ray absorption at the $\mathrm{Cd} K$-edge involves the dipole transition of a $\mathrm{Cd} 1 s$ electron to an unoccupied $5 p_{3 / 2,1 / 2}$ or $n p_{3 / 2,1 / 2}$ orbital. X-ray absorption fine structure (XAFS), especially its near edge region, X-ray absorption near edge structure (XANES) probe the unoccupied density of states in the conduction band and provide a detailed understanding of the oxidation state, coordination, and local chemical environment of the specific element being probed. ${ }^{25}$

X-ray excited optical luminescence (XEOL) has been shown to be a powerful tool for investigating the local chemical environment of a site that gives rise to a particular 
luminescence band. ${ }^{26}$ It has successfully been used to study the chemical origin of luminescence in porous $\mathrm{Si}, \mathrm{Si}$ nanowires, $\mathrm{SnO}_{2}$ nano-ribbons, $\mathrm{Ga}_{2} \mathrm{O}_{3}$ nanostructures, and $\mathrm{ZnS}$ nanostructures as well as $\mathrm{ZnO}-\mathrm{ZnS}$ and $\mathrm{Si}-\mathrm{CdSe}$ nano-heterostructures. $^{27-34}$ In XEOL, one monitors the intensity of the luminescent bands as the X-ray energy is raised above the core level binding energy of a particular element in the system, thereby exciting an electron from a core level to a previously unoccupied state in the conduction band. The decay of the excited state can give rise to more intense luminescence via energy transfer to the optical channel. Therefore, an increase in signal is seen at an energy corresponding to a particular local environment of the probed element.

In the present work, the electronic and optical properties of $\mathrm{CdS}_{\mathrm{x}} \mathrm{Se}_{1-\mathrm{x}}$ nanostructures with varying alloy compositions are examined with XEOL together with X-ray absorption near edge structure (XAFS) spectroscopy, including both the near edge region, XANES, and the extended X-ray absorption fine structure (EXAFS) region at the $\mathrm{Cd}, \mathrm{Se}$, and $\mathrm{S} K$-edge, and $\mathrm{Cd}, \mathrm{Se}$, and $\mathrm{S} L_{3,2}$-edges. The interpretation of the data is supported by theoretical simulations. It is found that the optical band-gap emission of these $\mathrm{CdS}_{\mathrm{X}} \mathrm{Se}_{1-\mathrm{x}}$ nanoribbons can be tuned to the range between that of pure $\mathrm{CdS}$ $(2.43 \mathrm{eV})$ and $\mathrm{CdSe}(1.74 \mathrm{eV})$ by changing the $\mathrm{S}$ and $\mathrm{Se}$ ratio. This gradual shift in (optical and structural) properties from $\mathrm{CdS}$ character to $\mathrm{CdSe}$ character is also seen in the electronic structure. Furthermore, excitation by an X-ray source was shown to result in defect emission not seen by excitation from a UV or laser source. ${ }^{8,15,18}$ The wavelength and intensity of defect emission are also shown to be dependent on the $\mathrm{S}$ to Se ratio. These results demonstrate the nature of the dopant-host relationship in mixed $\mathrm{CdS}_{\mathrm{X}} \mathrm{Se}_{1-\mathrm{x}}$ systems.

\section{EXPERIMENTAL}

The $\mathrm{CdS}_{\mathrm{x}} \mathrm{Se}_{1-\mathrm{x}}$ nanostructures were prepared in a horizontal tube furnace as previously described in literature. ${ }^{2,8,15,35}$ The as grown $\mathrm{CdS}_{\mathrm{x}} \mathrm{Se}_{1-\mathrm{x}}$ alloy products formed along a temperature gradient are depicted in Figure 1. The morphology and composition of the $\mathrm{CdS}_{\mathrm{x}} \mathrm{Se}_{1-\mathrm{x}}$ nanostructures were characterized by Scanning Electron Microscopy (SEM) with an Oxford Instruments INCA X-ray detector and Energy Dispersive X-ray Spectroscopy (EDX) on a LEO (Zeiss) 1540XB FIB. Detailed characterization of the composition and morphology is given elsewhere. ${ }^{2,8,15,35}$

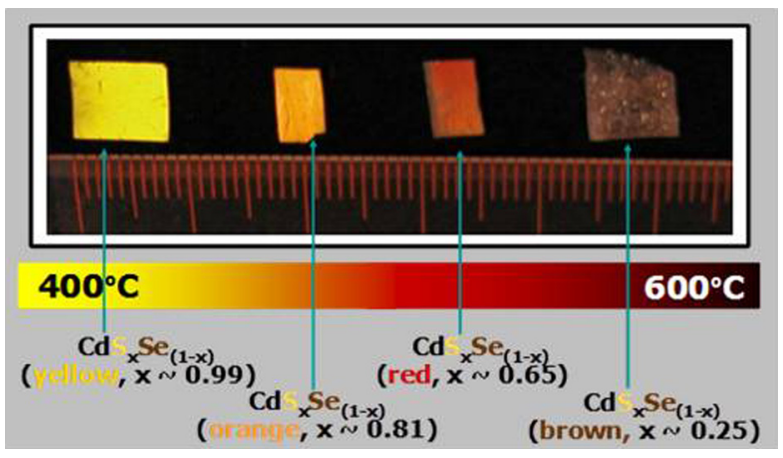

FIG. 1. Optical image correlating the composition of the $\mathrm{CdS}_{\mathrm{x}} \mathrm{Se}_{1-\mathrm{x}}$ nanostructures with the growth temperature gradient.
The XAFS and XEOL experiments at the Cd and Se $K$ edge were conducted at Pacific Northwest Consortium and $\mathrm{X}$-ray Science Division (PNC/XSD), Sector 20, bending magnet beamline 20-BM (3-27 keV, $\left.\Delta \mathrm{E} \sim 1 \times 10^{-4} \mathrm{keV}\right)$ of the Advanced Photon Source $(7 \mathrm{GeV}, 100 \mathrm{~mA}$ in top-up mode) at Argonne National Laboratories. $\mathrm{Cd} L_{3^{-}}$and $\mathrm{S}$ $K$-edges were performed at the Soft X-ray Micro-characterization beamline (SXRMB) 06B1-1 (1.7-10 keV, $\Delta \mathrm{E} / \mathrm{E} \sim 1$ $\left.\times 10^{-4}\right)$. Se $L_{3,2}$-edge was performed at the Spherical Grating Monochromator (SGM) beamline11ID-1 (250-2000 eV, $\Delta \mathrm{E} / \mathrm{E} \sim 1 \times 10^{-4}$ ) and $\mathrm{S} L_{3,2}$-edge was done at the Variable Line Spacing Plane Grating Monochromator (VLS-PGM) beamline 11ID-2 (5-250 eV, $\Delta \mathrm{E} / \mathrm{E}>1 \times 10^{-4}$ ) of the Canadian Light Source $(2.9 \mathrm{GeV}, 250 \mathrm{~mA})$ at the University of Saskatchewan, Saskatoon, Canada. The incident $\mathrm{X}$-rays irradiated the sample at normal incidence and the emitted photons were detected at $45^{\circ}$ from the incoming beam. The XEOL spectra were recorded using a USB400 Scientific-grade spectrometer (Ocean Optics) and a network CCD camera (Axis 2120). XANES spectra were recorded in total electron yield (TEY) and total fluorescence yield (FLY), using specimen current and a multi-channel plate detector, respectively. The optical-XAFS was recorded in photoluminescence yield (PLY) using an optical detector. All spectra were normalized to the incoming photon intensity $\left(\mathrm{I}_{0}\right)$ and the XAFS spectra were set to a uniform edge-jump.

\section{THEORETICAL CALCULATIONS}

The theoretical XANES spectra of core levels of interest for representative compositions and structures are calculated by the Density Functional Theory (DFT) using the WIEN2k program. The Generalized Gradient Approximation (GGA) ${ }^{36}$ or the modified Becke and Johnson (mBJ) exchangecorrelation potential $^{37}$ has been applied. The full potential augmented plane wave method has been used in the numerical calculation. ${ }^{38,39}$ The code has been built based on the density functional theory ${ }^{40,41}$ which provides an ab-initio method for calculating matter with a relatively homogeneous distribution of electrons around the atomic sites, together with the generalized gradient approximation having a first derivative correction. The crystal under consideration is divided into two regions: the atomic sites and the interstitial regions. For the atomics sites, it is described by a linear combination of the radial wave function and the energy derivative of this radial wave function multiplied by the non-overlapping spherical harmonics $Y_{l m}$. The interstitial regions are expressed by sets of 20000 plane waves. The boundary condition is satisfied by matching the function describing the atomic sites and the plane waves of the interstitial area at the boundary. Selfconsistent minimization of energy was achieved with $1000 \mathrm{k}$ points to obtain an equilibrium state of the material. The theoretical XANES spectra have been calculated using the electrical dipole transition and convoluted by instrumental Gaussian and core-hole lifetime Lorentzian broadenings. ${ }^{42}$

\section{EXPERIMENTAL RESULTS AND DISCUSSION}

A representative SEM image and EDX spectrum of the $\mathrm{CdS}_{\mathrm{X}} \mathrm{Se}_{1-\mathrm{x}}$ nanostructures are displayed in Figure 2 for the 


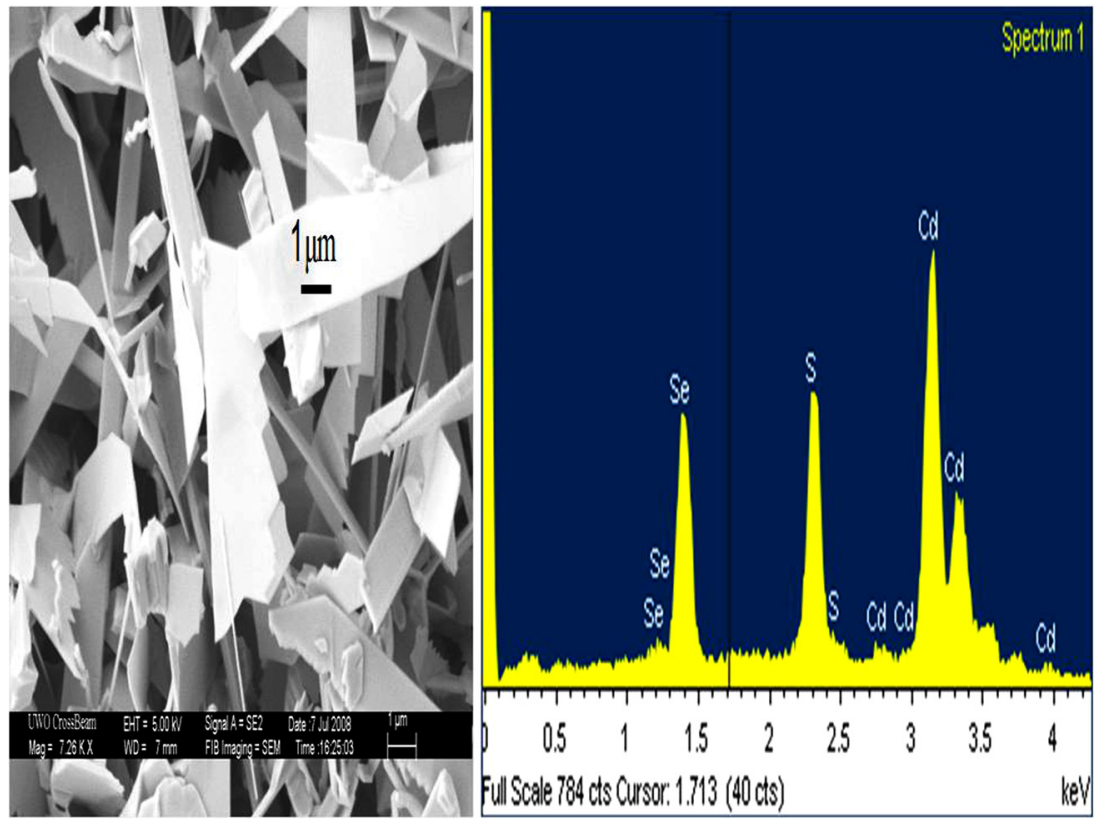

FIG. 2. SEM image and EDX spectrum (10 keV excitation) of $\mathrm{CdS}_{0.65} \mathrm{Se}_{0.35}$ nanostructure (Red).

$\mathrm{CdS}_{0.65} \mathrm{Se}_{0.35}$ (Red) sample. SEM images and EDX spectra for the remaining nanostructures can be found in the supplemental material (Figures S1 and S2). ${ }^{61}$ The compositions for the $\mathrm{CdS}_{\mathrm{x}} \mathrm{Se}_{1-\mathrm{x}}$ obtained from the EDX are $\mathrm{CdS}_{0.99} \mathrm{Se}_{0.01}$ (yellow), $\mathrm{CdS}_{0.81} \mathrm{Se}_{0.19}$ (orange), $\mathrm{CdS}_{0.74} \mathrm{Se}_{0.26}$ (red-orange), $\mathrm{CdS}_{0.65} \mathrm{Se}_{0.35}$ (red), and $\mathrm{CdS}_{0.25} \mathrm{Se}_{0.75}$ (brown) denoted by the color of appearance (Figure 1) and referred to hereafter as yellow, orange, red-orange, red, and brown, respectively, as the content of Se increases. The composition of the $\mathrm{CdS}_{\mathrm{x}} \mathrm{Se}_{1-\mathrm{x}}$ nanostructures varies with growth temperature and $\mathrm{x}$ decreases with growth temperature from $400{ }^{\circ} \mathrm{C}$ to $600{ }^{\circ} \mathrm{C}$ (Figure 1). The color change from yellow to brown as the content of Se increases in $\mathrm{CdS}_{\mathrm{x}} \mathrm{Se}_{1-\mathrm{x}}$ is due to the change of light absorption with the incident visible wavelength as $\mathrm{x}$ changes. The color is affected by particle size, shape, and method of preparation (band gap change). Cadmium selenide and cadmium sulfide form continuous solid solutions of the substitution type. The color formed and other physical properties are a linear function of the solvent-to-solute proportion. $^{43}$ Additionally, the morphology of the nanostructures varies slightly with composition and growth temperature. The middle of the temperature gradient is dominated by a nano-ribbon morphology while both ends of the temperature range contain a mixture of nano-ribbons and nano-wires. A more detailed analysis of the structure and morphology can be found in the literature. . $^{2,8,15,35}$

\section{A. The Se K-edge EXAFS}

Figure 3(a) shows the Se $K$-edge FLY EXAFS. The backscattering amplitude of the $\mathrm{CdS}_{\mathrm{x}} \mathrm{Se}_{1-\mathrm{x}}$ nanostructures is similar from the mid to high $k$ region and therefore results in similar EXAFS signal. ${ }^{44}$ The Fourier transforms of the Se $K$ edge EXAFS performed over the range of $3 \leq k \leq 10 \AA^{-1}$ are
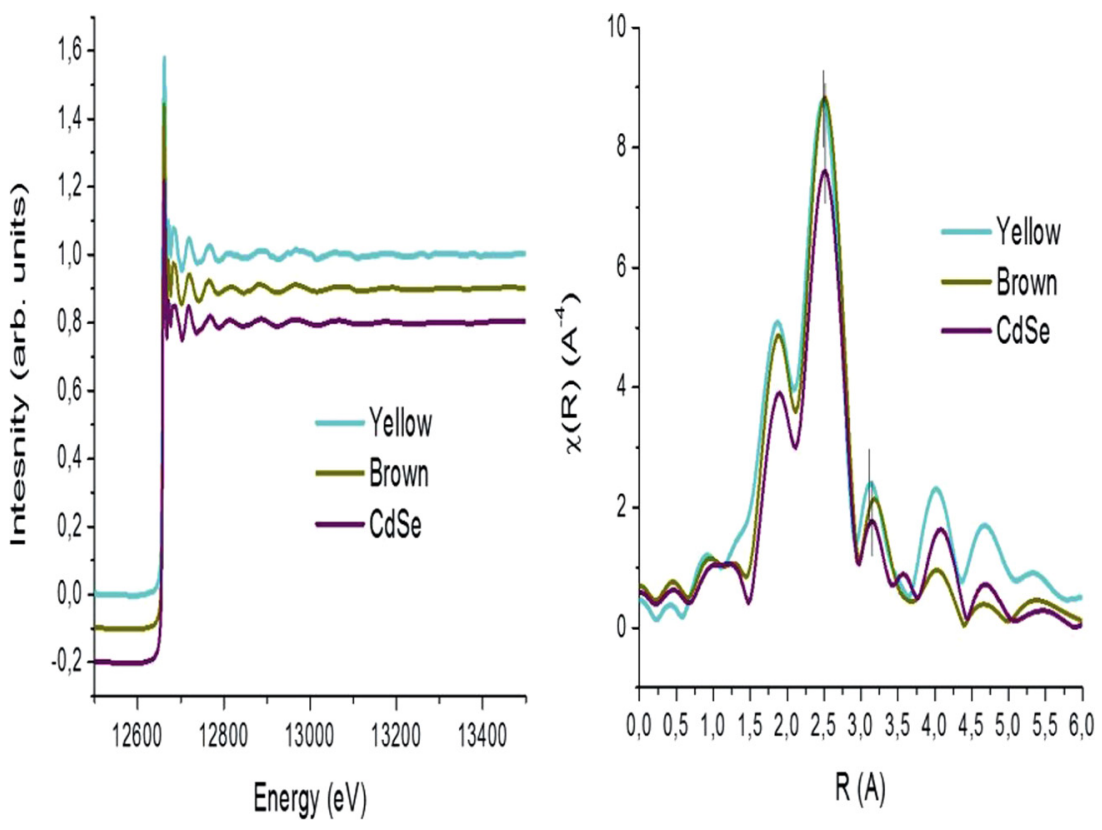

FIG. 3. (a) Se $K$-edge EXAFS in FLY of $\mathrm{CdS}_{\mathrm{x}} \mathrm{Se}_{1-\mathrm{x}}$ nanostructures. (b) Fourier Transform of the Se $K$-edge EXAFS of $\mathrm{CdS}_{\mathrm{x}} \mathrm{Se}_{1-\mathrm{x}}$ nanostructures plotted in radial distribution (no phase correction, $\mathrm{k}^{3}$ weighted). 
shown in Figure 3(b). The strong peak at $2.52 \AA$ is ascribed to the nearest $\mathrm{Se}-\mathrm{Cd}$ bond while the side lobe at $1.88 \AA$ arises from the nonlinearity in the phase-shift of the $\mathrm{Cd}$ scatterer in $\mathrm{k}$ space. ${ }^{22,44,45}$ These results are consistent with previous studies of Se EXAFS in CdSe. ${ }^{22,45,46}$ This suggests that the distance to the first neighbour shell around $\mathrm{Se}$ ( $\mathrm{Se}-\mathrm{Cd}$ pair) in the $\mathrm{CdS}_{\mathrm{x}} \mathrm{Se}_{1-\mathrm{x}}$ samples corresponds to the Se-Cd pair distance in CdSe. This similarity is expected given that the difference in nearest neighbour distance in bulk CdSe $(2.630 \AA)$ and bulk $\operatorname{CdS}(2.542 \AA)$ is only $\sim 0.1 \AA .{ }^{47,48}$ This suggests the incorporation of Se into a CdS matrix and $\mathrm{S}$ into a CdSe matrix results in minimal local distortion and disorder to the lattice and minimal change in the Se-Cd bond distance. The insertion of Se into CdS does not cause any phase change of the composite $\mathrm{CdS}_{\mathrm{x}} \mathrm{Se}_{1-\mathrm{x}}$ material.

\section{THEORETICAL XANES IN COMPARISON WITH EXPERIMENTAL XANES}

\section{A. The Cd K and L-edge XANES}

The XANES edges of CdS, CdSe, and a representative solid solution, $\mathrm{CdS}_{0.5} \mathrm{Se}_{0.5}$ (henceforth denoted $\mathrm{CdSSe}$ ) have been evaluated by WIEN2k. The results with GGA calculation have been previously reported by Yiu et al. ${ }^{49}$ The selfconsistent calculation with $\mathrm{mBJ}$ potential is incorporated here. Representative values of the core-hole level widths are $\mathrm{Cd} K, 7.28 \mathrm{eV}$; $\mathrm{Cd} L_{3}, 2.5 \mathrm{eV}$; $\mathrm{Cd} L_{2}, 2.62 \mathrm{eV} ; \mathrm{S} K, 0.59 \mathrm{eV}$; $\mathrm{S} L_{3}$ and $L_{2}, 0.05 \mathrm{eV}$; Se $K, 2.33 \mathrm{eV}$; Se $L_{3}, 1.0 \mathrm{eV}$; and $\mathrm{Se}$ $L_{2}, 1.13 \mathrm{eV}^{42}$

Fig. 4(a) shows the $\mathrm{Cd} K$ edge and Fig. 4(b) illustrates $\mathrm{Cd} L_{3}$ edge of CdS and CdSe with the theoretical XANES spectra calculated by DFT together with the $\mathrm{mBJ}$ potential. With GGA calculation, the experimental $\mathrm{Cd} L_{3}$ edge of both $\mathrm{CdS}$ and CdSe favours the B4 wurtzite structure as the preedge region indicates the presence of small peaks, peak $A$ and peak B. ${ }^{49}$ They compared favourably to the theoretical GGA curves of the B4 structure. However, with mBJ potential, there is neither peak A nor peak B in the calculated $\mathrm{Cd}$
$L_{3}$ edge. Peak $\mathrm{C}$ of the $\mathrm{Cd} K$ edges of CdSe in Figure 4(a) moves closer to the edge compared to that of $\mathrm{CdS}$ due to the larger Se atom and thus longer $\mathrm{Cd}-\mathrm{Se}$ inter-atomic distance. Peak E of the Cd L-edge of CdSe in Figure 4(b) also gets closer to the edge than that of CdS.

The XANES of the $\mathrm{CdS}_{\mathrm{x}} \mathrm{Se}_{1-\mathrm{x}}$ nanostructures at the $\mathrm{Cd}$, $\mathrm{S}$, and $\mathrm{Se}, K$-edge $(1 s \rightarrow \mathrm{n} p$ dipole transitions $)$ and $L$ edge $\left(2 p_{3 / 2} \rightarrow \mathrm{n} d\right)$ have been accumulated and analyzed. ${ }^{49}$ For $\mathrm{Cd}$ $K$-edge, the energy of the white-line is consistent for all samples. However, a change in the multiple scattering and early EXAFS region, where peaks can be seen with a dampening in peak intensity, is moving from $\mathrm{CdS}$ toward CdSe in composition particularly in the peak at $\sim 26785 \mathrm{eV}$. This is accompanied by the emergence of a weaker peak at lower energy. This change can be understood in terms of the backscattering amplitude of $\mathrm{S}$ and $\mathrm{Se}$, of which Se has a noticeably smaller amplitude in the low $\mathrm{k}$ region, and the larger Se atom (a longer Cd-Se inter-atomic distance). ${ }^{44}$

Although previous studies have shown that there is a shift in the edge position to higher energy going from $\mathrm{Cd}^{2+}$ ion in solution to $\mathrm{CdO}$ to $\mathrm{CdS}$, there appears to be no noticeable difference in the edge position when moving from $\mathrm{CdS}$ to $\mathrm{CdSe} .^{50,51}$ Similar results have been seen in mixed $\mathrm{CdTe}_{\mathrm{x}} \mathrm{S}_{1-\mathrm{x}}$ systems where there is no change in edge position with composition. ${ }^{52}$ The edge shift relates to the ionic and covalent nature (and related crystal structure) of the compounds where $\mathrm{Cd}^{2+}$ and $\mathrm{CdO}$ (rock-salt) are ionic-like in character while $\mathrm{CdS}$ (wurtzite), CdSe (wurtzite), and CdTe (wurtzite) systems are covalent-like in character. This indicates that the net charge transfer from the $\mathrm{Cd}$ to $\mathrm{S}$ or $\mathrm{Se}$ in the $\mathrm{CdS}_{\mathrm{x}} \mathrm{Se}_{1-\mathrm{x}}$ nanostructures is very similar; that is, that the $\mathrm{Cd}^{2+}$ is much better screened in the covalent system and can be denoted as $\mathrm{Cd}(\mathrm{II})$.

\section{$B$. The $S K$ and $L$-edges}

$\mathrm{S} K$ edge and $L_{3,2}$ edges of $\mathrm{CdS}$ are shown in Figs. 5(a) and $5(\mathrm{~b})$, respectively. The theoretical XANES spectra have been calculated by the $\mathrm{mBJ}$ potential. Peak $\mathrm{E}$ of the
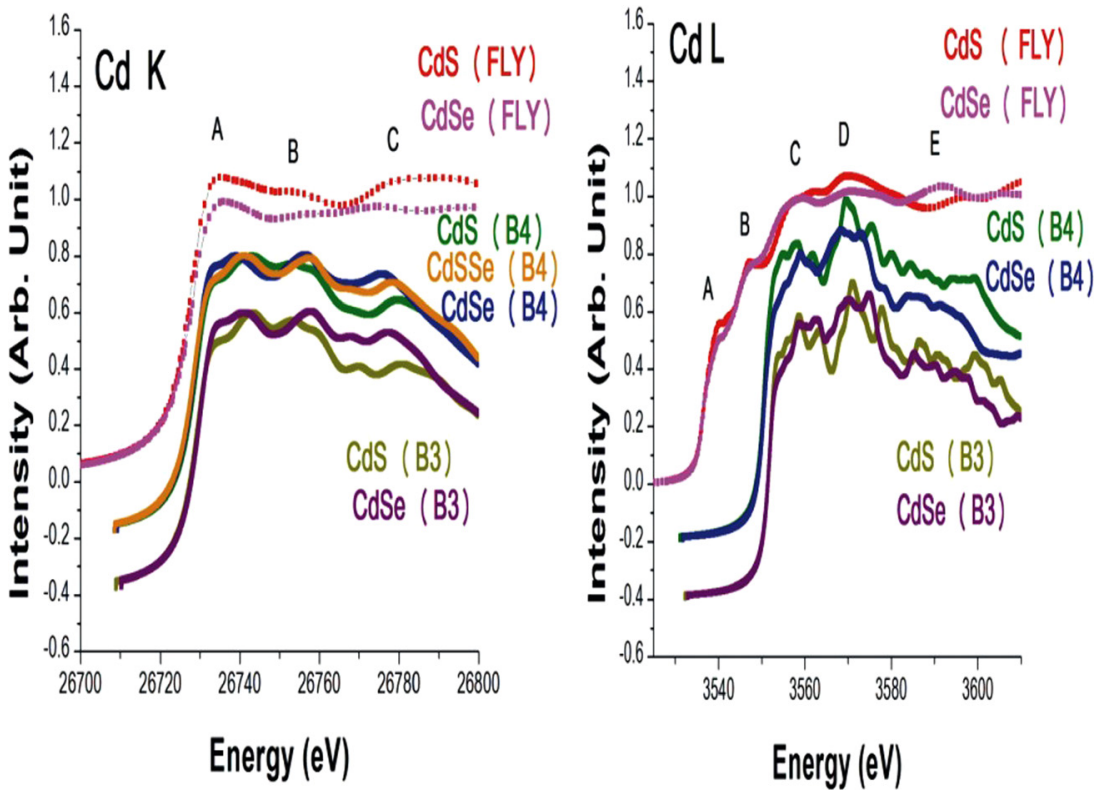

FIG. 4. Experimental and theoretical XANES of CdS and CdSe: (a) Cd $K$ edge and (b) $\mathrm{Cd} L_{3}$ edge using $\mathrm{mBJ}$ potential. 

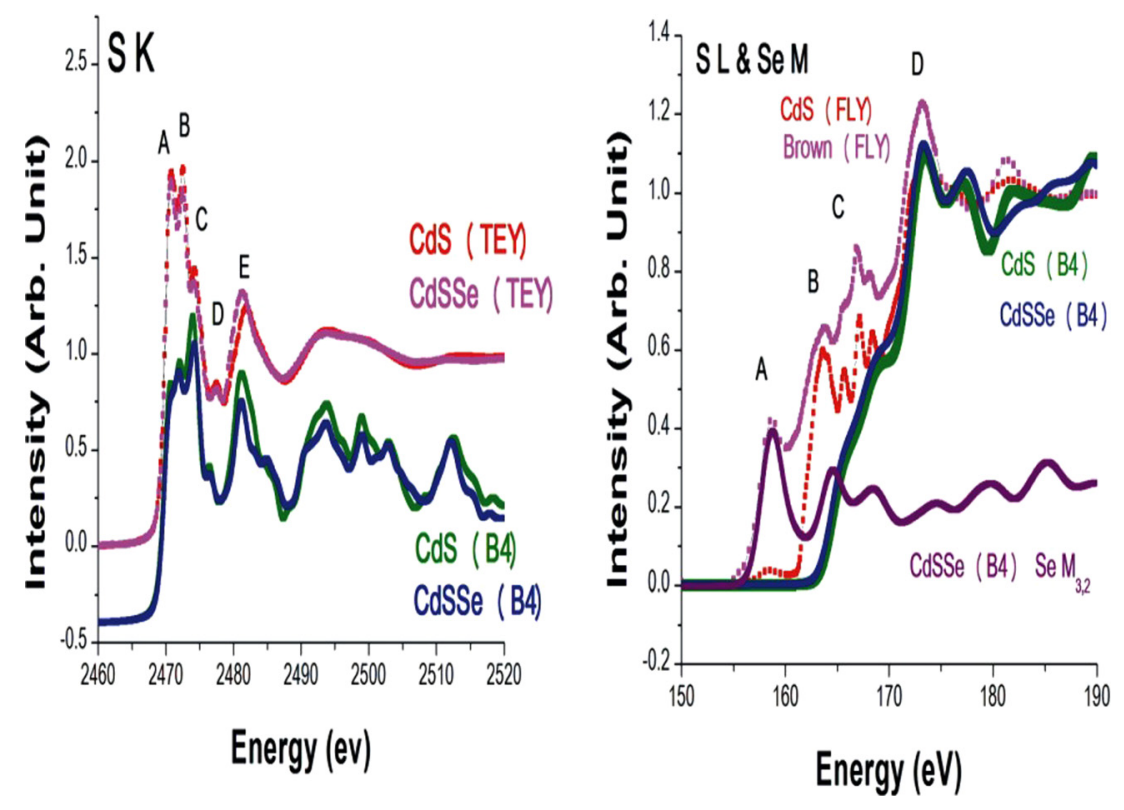

FIG. 5. Experimental and theoretical (by $\mathrm{mBJ}$ potential): (a) $\mathrm{S} K$ and (b) $\mathrm{S}$ $L_{3,2}$ and Se $M_{3,2}$ XANES of CdS and CdSSe.

theoretical $\mathrm{S} K$ edge XANES in Figure 5(a) is in good agreement with the experimental TEY, indicating that no surface oxidation occurs in these samples since the theoretical CdS and $\mathrm{CdS}_{0.5} \mathrm{Se}_{0.5}$ models are hexagonal $\mathrm{B} 4$ crystals with no oxides. Peak A preceding the $\mathrm{S} L$ edge region of $\mathrm{CdS}$ in Figure 5(b) corresponds to the $\mathrm{Se} M_{3}$ peak. In Figure 5(b), peak $\mathrm{B}$ is attributed partly to Se $M_{2}$ and $\mathrm{S} L_{3}$ edges, where Peaks $\mathrm{C}$ and $\mathrm{D}$ are due to the $\mathrm{S} L_{3}$ edges.

Figure 5(a) shows the TEY XANES, taken at the S $K$ edge of CdS, and CdSSe samples. A few important features are noted: First, the intense peak $A$ seen in all three spectra, at $2470.5 \mathrm{eV}$, corresponds to the $\mathrm{S} K$-edge jump of the sulphide $\left(\mathrm{S}^{2-}\right)$ species, assigned to an electron transition from the $\mathrm{S} 1 s$ core to an empty $\mathrm{S} 3 p$-like state in the valence band. ${ }^{53}$ Similarly, peaks $B, C$, and $D$ are also related to dipole transitions from the $\mathrm{S} 1 s$ to unoccupied orbitals that are $\mathrm{S} p$-like in character. ${ }^{53}$ The spectral features at energies higher than peak $E$ are most likely from single-scattering events (EXAFS). Since the spectral features of the yellow and orange match that of $\mathrm{CdS}$, the local environment of the $\mathrm{S}$ is very similar in all three systems. ${ }^{49}$ Although, closer examination of the multiple scattering peak of the orange reveals that it is shifted closer to the threshold, which qualitatively indicates a slightly longer $\mathrm{S}$ bond when Se becomes a more dominant component in the lattice. The appearance of a sharp intense peak slightly blue shifted relative to peak $E$ has been previously attributed to the oxidation of the sulphide forming $\mathrm{S}-\mathrm{O}$ bonds probably in the form of sulphate $\left(\mathrm{SO}_{4}{ }^{2-}\right)$ upon exposure to air, ${ }^{54-57}$ however no such surface oxidation occurs in these samples.

Figure 5(b) shows the FLY-XANES spectra of the $\mathrm{CdS}_{\mathrm{x}} \mathrm{Se}_{1-\mathrm{x}}$ nanostructures at the $\mathrm{S} L_{3,2}$-edge $\left(\mathrm{S} 2 p_{3 / 2,1 / 2} \rightarrow 4 s\right.$, $3 d$ transitions $)$. At the $L_{3}(163.5 \mathrm{eV})$ absorption edge, there is an intense absorption (white-line) in the FLY. The peak profile at the $\mathrm{S} L_{3,2}$-edge is very similar for all CdSSe samples providing evidence that the $S$ is in a comparable local environments for all the systems. The main difference observed in the CdSSe nanostructures is the intensity of the pre-edge peak at $158.5 \mathrm{eV}$. This pre-edge peak is due to the presence of surface defect states which exist just below the conduction band. It is also possible that they arise from the $L_{1}$-edge of $\mathrm{Si}$ from the substrate or the $M_{3,2}$ edge of $\mathrm{Se}$ although Si is not detected from EDX (Figure 2) and theoretical calculation suggests the latter. The intensity of the preedge feature is the highest for the nanostructures with the highest surface area to volume ratio, and it is most intense for orange than brown which consist of small nano-wires. ${ }^{49}$ The pre-edge decreases for the small yellow nanostructures and more so for the larger red-orange and red nano-ribbons, then almost disappears for the bulk CdS powder.

\section{The Se $K$ and L-edge}

Figs. 6(a) and 6(b) show the Se $K$ and $L_{3,2}$ edges of $\mathrm{CdSSe}$ nanostructures, respectively, and the theoretical spectra have been calculated by the $\mathrm{mBJ}$ potential. Whitelines of the theoretical Se $K$-edge XANES spectra are more pronounced than the experimental FLY. The reduction of the intensity of FLY may be in some case due to the thickness effect of the samples. Since our samples are only a few microns thick, the reduction of FLY is not due to the thickness of the samples. The area under the whiteline is proportional to the densities of states of $p$ holes in the Se $p$ band that crosses the Fermi level. This indicates that there may be less un-occupied $p$ state in the experimental CdSe sample. However, experimental broadening due to photon resolution, which is often small compared to corehole lifetime cannot be totally ruled out. Whiteline is slightly less pronounced for the theoretical $\mathrm{Se} L_{3}$ XANES spectra which show that there are more unoccupied $s$ and $d$ states of the experimental samples. This indicates that the $s-p$ hybridization of Se in the valence band is in favor of larger $p$ character.

The Se $K$-edge FLY XANES of the $\mathrm{CdS}_{\mathrm{x}} \mathrm{Se}_{1-\mathrm{x}}$ nanostructures are displayed in Figure 6(a). The Se $1 s \rightarrow \mathrm{n} p$ dipole transition at the Se $K$-edge threshold results in a sharp absorption peak (white-line). The position of the white-line is related to the formal charge at the Se site and the area under the peak is representative of the densities of 


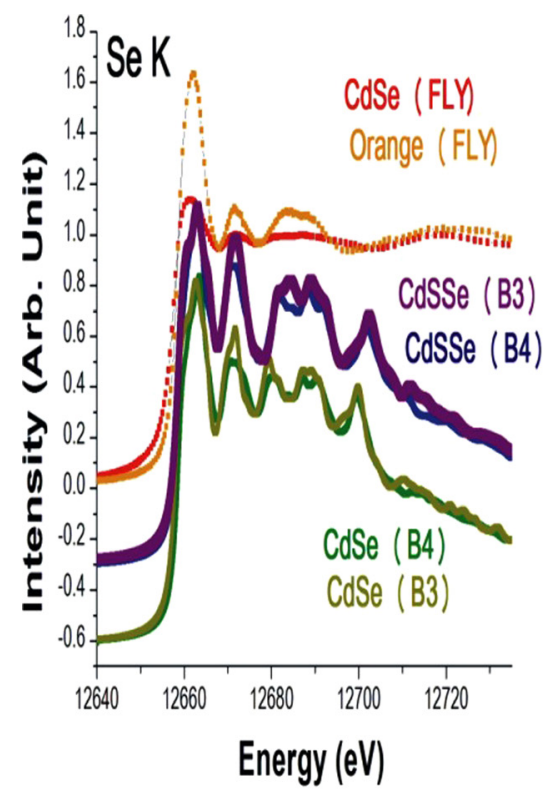

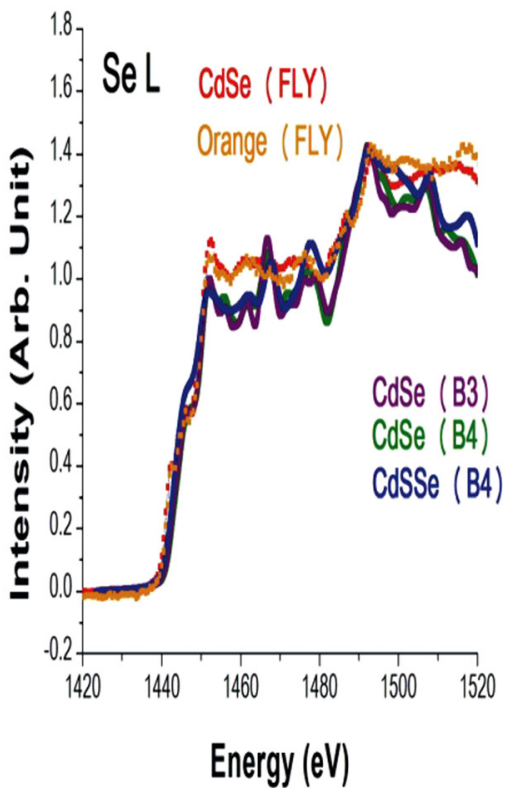

FIG. 6. Experimental and theoretical (by mBJ potential): (a) $\mathrm{Se} K$ and (b) $\mathrm{Se}$ $L_{3,2}$ XANES of CdSe and CdSSe. unoccupied states of primarily Se $4 p$ character (amount of Se $4 p$ holes in the conduction band). The multiple scattering resonance features up to $50 \mathrm{eV}$ beyond the white-line are characteristic of the local environment of the absorbing Se atom. ${ }^{58,59}$ Comparing Se $K$-edge XANES of the $\mathrm{CdS}_{\mathrm{x}} \mathrm{Se}_{1-\mathrm{x}}$ nanostructures and with $\mathrm{CdSe}$ powder, there is a noticeable shift in the white-line to higher energy with increasing $\mathrm{S}$ content moving from CdSe $(12661.2 \mathrm{eV})$ to yellow $(12662.0 \mathrm{eV}) .^{49}$ The binding energy of the Se increases from $\mathrm{CdSe}$ to yellow, when it is incorporated in a less favorable environment, such as a more CdS like wurtzite matrix. $\mathrm{S}$ is more electronegative than $\mathrm{Se}$ and will act as an electron withdrawing group and thus $\mathrm{Cd}$ will donate more electron density to the surrounding $S$ than the Se. Therefore, the higher the $\mathrm{S}$ content in the system the lower the electron density of the Se and the higher the Se binding energy. Additionally, the resulting removal of electron density from the Se through the addition of $S$ as well as the increase in surface Se with dangling bonds due the decrease in size of the nanostructures compared to bulk CdSe means there is an increase in the Se $4 p$ holes. These holes are unoccupied states of $4 p$ character in the conduction bands. This results in an increase in the white-line intensity as seen in Figure 6(a). Similar shifts in the white-line to higher energy and intensity can be seen in CdSe nano-particles capped with electron withdrawing ligands. ${ }^{59}$ The position of the multiple scattering resonances is identical for all the $\mathrm{CdS}_{\mathrm{x}} \mathrm{Se}_{1-\mathrm{x}}$ samples and the CdSe powder standard indicating that the Se is tetrahedrally coordinated to $\mathrm{Cd}$ in a wurtzite crystal structure for all samples.

The theoretical calculation of DFT together with GGA or $\mathrm{mBJ}$ potential gives a consistent interpretation of the XANES edges of CdSSe samples at $\mathrm{Cd} K, \mathrm{Cd} L_{3,2}, \mathrm{~S} \mathrm{~K}, \mathrm{~S}$ $L_{3,2}$ and Se $K$, Se $L_{3,2}$, and Se $M_{3,2}$ edges. The experimental $\mathrm{Cd} L_{3}$ edge of both $\mathrm{CdS}$ and $\mathrm{CdSe}$ compared favourably to the theoretical DFT together with GGA curves of the B4 hexagonal structure, as the pre-edge region indicates the presence of small peaks, peak $\mathrm{A}$ and peak B. ${ }^{49}$ These small peaks are also present in all the $\mathrm{CdS}_{\mathrm{x}} \mathrm{Se}_{1-\mathrm{x}}$ samples and indicate that these samples are all in hexagonal phase and that no phase change occurs for these $\mathrm{CdS}_{\mathrm{x}} \mathrm{Se}_{1-\mathrm{x}}$ samples during preparation. At $\mathrm{S} L_{3,2}$ and Se $M_{3,2}$ edges, DFT theory shows the contribution of Se $M_{3,2}$ edges near $\mathrm{S} L_{3,2}$ edges.

The theoretical calculation of DFT is based on model crystals with no thermal motion of the material, considering the nuclei at their equilibrium positions. In general, the intensity of the dominant main-edge peak in ordered materials appears to be greater, relative to the edge jump, than in disordered materials of a given composition. Disorder due to finite temperature typically broadens spectra without altering the overall integrated strength as is shown in the experimental XANES spectra.

\section{EXPERIMENTAL XEOL RESULTS AND DISCUSSIONS}

All the XEOL spectra (Figures 7(a)-7(c)) exhibit two emission bands. The sharper band is the band-gap emission (excitonic), while the broad band is the defect emission of the $\mathrm{CdS}_{\mathrm{x}} \mathrm{Se}_{1-\mathrm{x}}$ nanostructure. The broadening and slightly varying centroid position are due to the distribution of the defects in contrast to a well-defined near band gap optical emission. This defect emission has not been previously observed in conventional PL studies using laser excitations. ${ }^{8,15,18}$ This implies that the use of X-rays opens the possibility of new de-excitation channels inaccessible by laser sources which do not provide enough energy transfer to produce defect luminescence. XEOL is largely based on thermalization of energetic electrons produced locally at the site of interest. From the XEOL spectra in Figure 7, there is a tunable red shift in both the band-gap and defect emissions with decreasing $\mathrm{S}$ or increasing Se content in the $\mathrm{CdS}_{\mathrm{x}} \mathrm{Se}_{1-\mathrm{x}}$ nanostructures. It is known that the band-gap of $\mathrm{CdS}_{\mathrm{x}} \mathrm{Se}_{1-\mathrm{x}}$ alloys can be determined by an interpolation between those of the two binaries ( $\mathrm{CdS}$ and $\mathrm{CdSe}$ ) with an additional nonlinear bowing parameter $^{60}$ according to the following equation: 

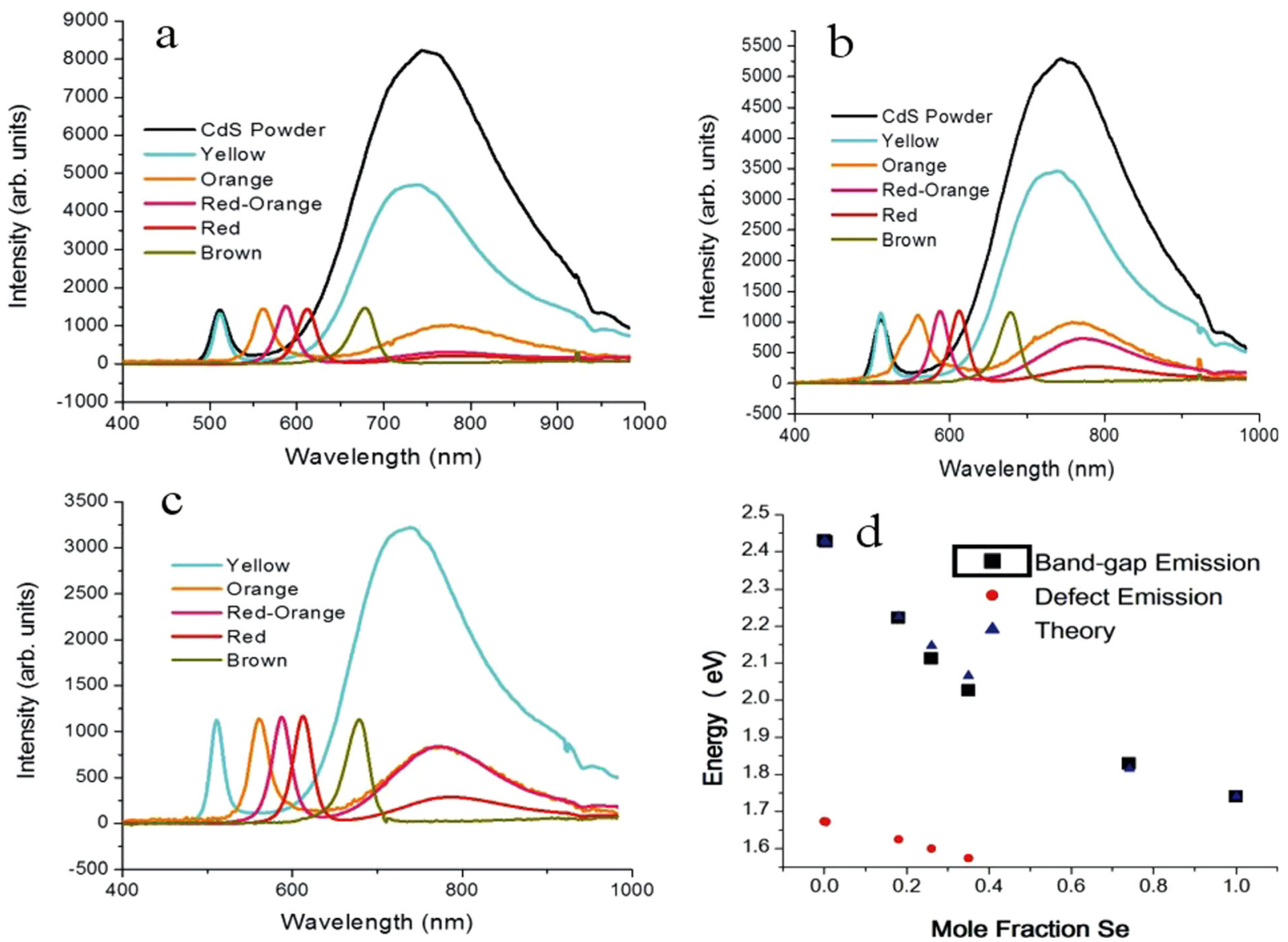

FIG. 7. S $L_{3}$-edge XEOL spectra of $\mathrm{CdS}_{\mathrm{x}} \mathrm{Se}_{1-\mathrm{x}}$ normalized to the maximum band-gap intensity when excited at $155 \mathrm{eV}$ (a), $163.5 \mathrm{eV}$ (b), $170 \mathrm{eV}$ (c), and the maximum of band-gap and defect emission energy as a function of mole fraction Se for the $163.5 \mathrm{eV}$ excitation (d). Note: The spectral response observed at $\sim 930 \mathrm{~nm}$ is an artifact of the detector.

$E_{g}\left(C d S_{x} S e_{1-x}\right)=x E_{g}(C d S)+(1-x) E_{b}(C d S e)-x(1-x) b$

where, $E_{\mathrm{g}}(\mathrm{CdS})$ is $2.43 \mathrm{eV}, E_{\mathrm{g}}(\mathrm{CdSe})$ is $1.74 \mathrm{eV}$, and the bowing parameter $b$ is 0.54 for $\mathrm{CdS}_{\mathrm{X}} \mathrm{Se}_{1-\mathrm{x}}$ at room temperature. Using the alloy composition $x$ determined by EDX, the theoretical band-gap values of the nanostructures for each composition $x$ can be determined. The theoretical band-gap energies (blue triangles) along with the experimental bandgap energies (black squares) and defect emission energies (red circles) are plotted in Figure 7(d). The theoretical values are in good agreement with the experiment band-gap energies. The small deviation in the red-orange and red samples can be attributed to different sampling depths/sizes between the EDX (micrometers). XEOL at the $\mathrm{S} L_{3}$-edge (tens of nanometers) results in a minor discrepancy in composition which could be slightly different at the surface of the nanostructures and vary along the length of the substrate (Figure 1).

The peaks of the band gap emission from the XEOL spectra of CdS, yellow, orange, red-orange, red, and brown samples are at $511.32 \mathrm{~nm}, 551.446 \mathrm{~nm}, 562.984 \mathrm{~nm}$, $587.541 \mathrm{~nm}, 612.02 \mathrm{~nm}$, and $678.19 \mathrm{~nm}$, respectively. The peak positions of the band gap emission of these samples do not change when the excitation energy is tuned through the $\mathrm{S}$ L-edge, changing from $155 \mathrm{eV}, 163.5 \mathrm{eV}$, and
$170 \mathrm{eV}$. The corresponding band gaps of $\mathrm{CdS}$, yellow, orange, red-orange, red, and brown samples are $2.43 \mathrm{eV}$, $2.25 \mathrm{eV}, \quad 2.20 \mathrm{eV}, \quad 2.11 \mathrm{eV}, 2.03 \mathrm{eV}$, and $1.83 \mathrm{eV}$, respectively.

The band gaps of CdS, CdSSe and CdSe have also been calculated using the mBJ exchange-correlation potential ${ }^{37}$ within the frame work of WIEN2k. The calculated band gaps are $\quad \mathrm{E}_{\mathrm{g}}(\mathrm{CdS}-\mathrm{B} 4)=2.55 \mathrm{eV}, \quad \mathrm{E}_{\mathrm{g}}\left(\mathrm{CdS}_{0.5} \mathrm{Se}_{0.5}-\mathrm{B} 4\right)=2.25 \mathrm{eV}$, $\mathrm{E}_{\mathrm{g}}(\mathrm{CdSe}-\mathrm{B} 4)=1.77 \mathrm{eV}, \mathrm{E}_{\mathrm{g}}(\mathrm{CdS}-\mathrm{B} 3)=2.42 \mathrm{eV}, \mathrm{E}_{\mathrm{g}}(\mathrm{CdSe}-\mathrm{B} 3)$ $=1.74 \mathrm{eV}$. Both the local density approximation (LDA) and GGA underestimate band gaps ${ }^{49}$ and the mBJ potential improves the band gaps estimates, and the calculated $\mathrm{mBJ}$ band gaps are closer to the experimental data.

Additionally, it is clear that there is an increase in the branching ratio between the band-gap and defect emissions of the $\mathrm{CdS}_{\mathrm{x}} \mathrm{Se}_{1-\mathrm{x}}$ nanostructures with a decrease in the $\mathrm{S}$ to Se ratio. By probing the change in optical emission across the $\mathrm{S} L_{3}$-edge (Figure 7) of $\mathrm{CdS}$ and yellow, the defect emission decreases across the $\mathrm{S} L_{3}$-edge, whereas for orange, red-orange, and red, the defect emission increases across the $\mathrm{S} L_{3}$-edge. Moreover, there is a decrease in band-gap intensity moving from below the edge to the edge-jump $(163.5 \mathrm{eV})$ for the yellow, orange, red-orange, and red nanostructures and an increase for the brown. It is evident from these results that with deviation from pure $\mathrm{CdS}$, the $\mathrm{S}$ takes a more dominant role in defect emission. 

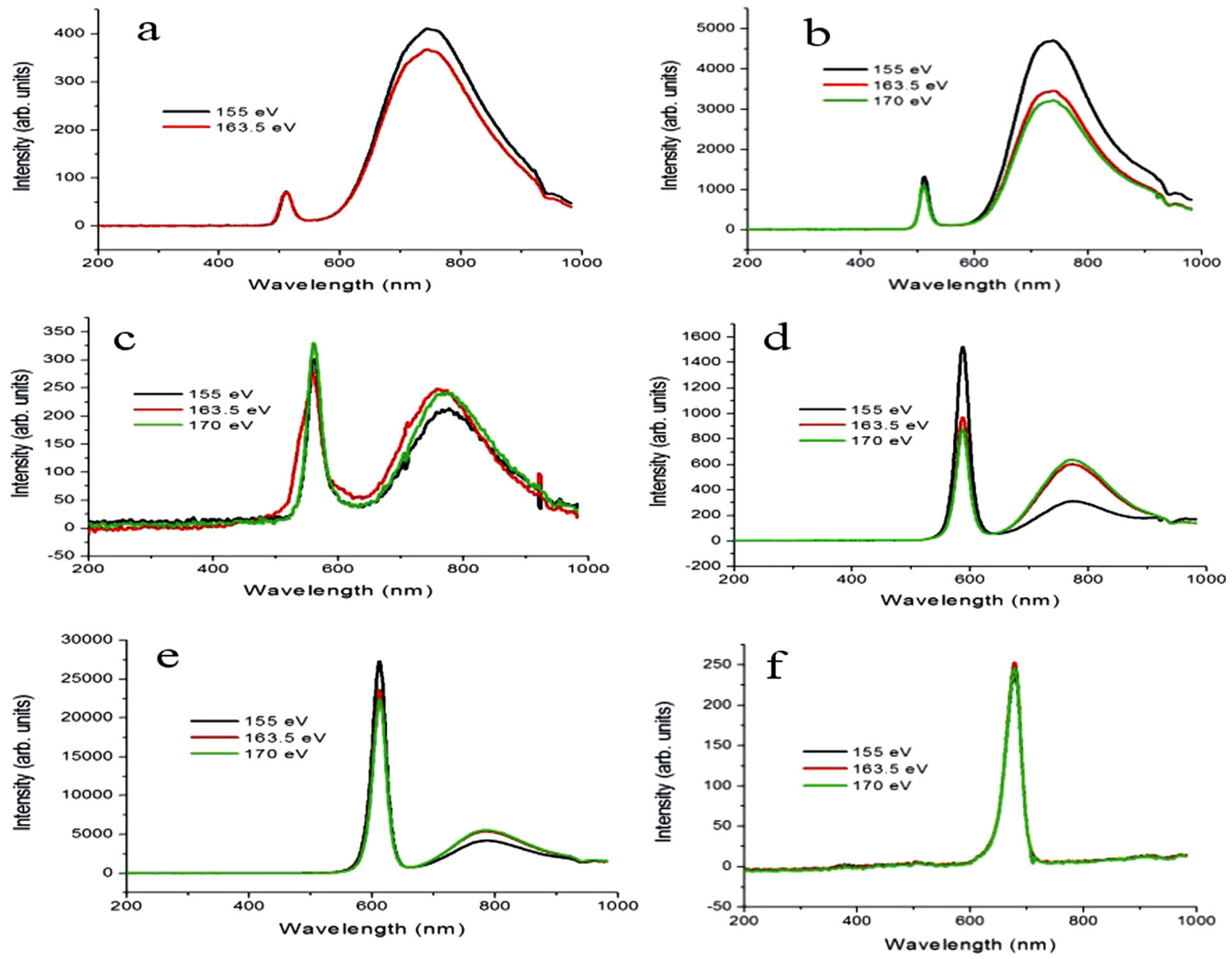

FIG. 8. S $L_{3}$-edge XEOL spectra for (a) CdS, (b) yellow, (c) orange, (d) red-orange, (e) red, (f) brown. The XEOL spectra are all corrected to the intensity of the incoming photons. Note: The spectral response observed at $\sim 930 \mathrm{~nm}$ is an artifact of the detector.

The decrease in band-gap emission across the $\mathrm{S} L_{3}$-edge indicates that the band-gap luminescence from the nanostructures is either more likely to originate from the $\mathrm{Cd}$ sites than the $\mathrm{S}$ sites or an abrupt change in sampling depth above the edge. The radiative channel is suppressed by the increasing presence of $\mathrm{Se}^{52}$
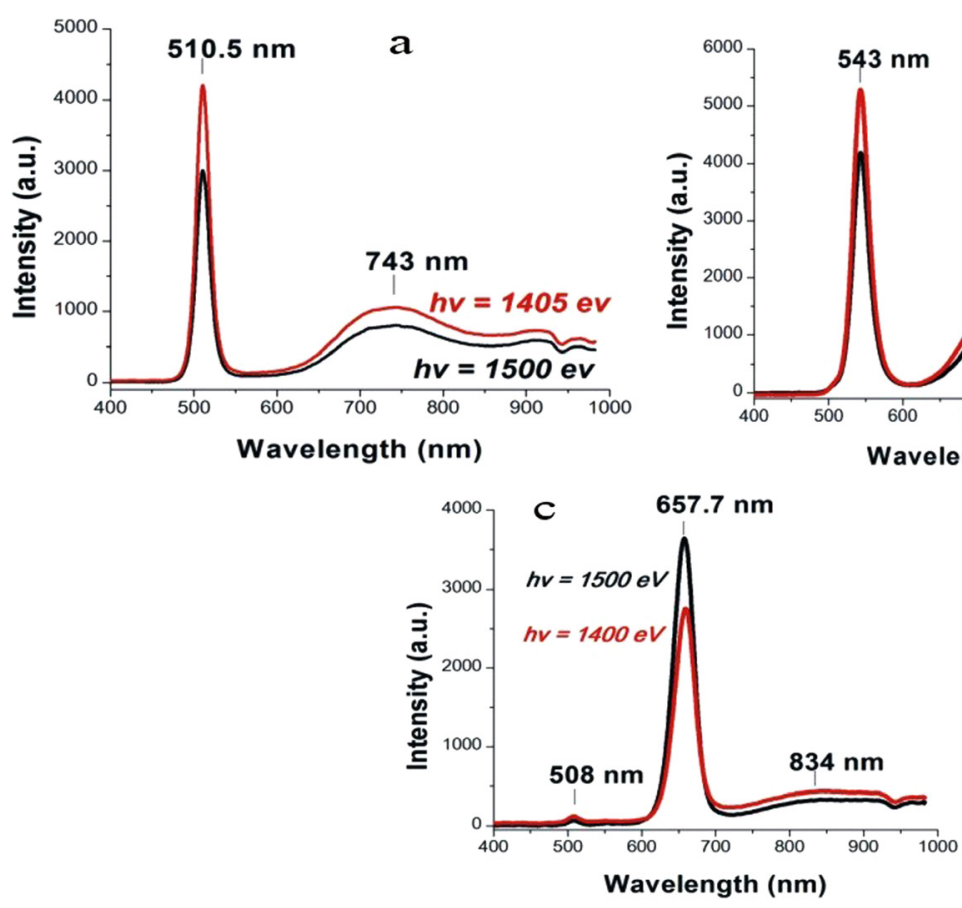

FIG. 9. Se $L_{3,2}$-edge XEOL of $\mathrm{CdS}_{\mathrm{x}} \mathrm{Se}_{1-\mathrm{x}}$ nanostructures: (a) yellow, (b) orange, and (c) brown. Note: The spectral response observed around $930 \mathrm{~nm}$ is an artifact of the detector. 
Figure 8 shows the $\mathrm{S} L$-edge XEOL excited across the edge. Of particular interest is the organge sample which exhibits a shoulder at shorter wavelength region in the near band gap emission when the system is excited at the $\mathrm{S} L_{3}$ edge resonance. See supplemental material Figure S3 for the spectral fits. ${ }^{61}$

Figures 9(a)-9(c) show the XEOL spectra taken at excitation energies below the $\mathrm{Se} L_{3}$-edge $(1405 \mathrm{eV})$ and above the $\mathrm{Se} L_{2}$-edge $(1500 \mathrm{eV})$ for the yellow, orange, and brown $\mathrm{CdS}_{\mathrm{x}} \mathrm{Se}_{1-\mathrm{x}}$ nanostructures. The peak positions of the band gap emission below the $S e L_{3}$-edge $(1405 \mathrm{eV})$ and above the Se $L_{2}$-edge $(1500 \mathrm{eV})$ are $510.5 \mathrm{~nm}, 543 \mathrm{~nm}$, and $657.7 \mathrm{~nm}$ for the yellow, orange, and brown samples, respectively. The corresponding band gap energies of the yellow, orange, and brown samples are $2.43 \mathrm{eV}, 2.28 \mathrm{eV}$, and $1.89 \mathrm{eV}$, respectively. The peak positions in the XEOL at the $\mathrm{Se} L_{3,2}$-edge differ slightly to those at the $\mathrm{S} L_{3,2}$-edge because they were recorded at different spots on the respective yellow, orange, and brown samples which have a minor variation in composition along the sample due to the growth gradient (see Figure 1). At the Se $L_{3,2}$-edge, there is a decrease in defect emission going from below to above the edge. The yellow and orange samples, which are closer to CdS, show a decrease in band-gap emission and band-gap to defect branching ratio. The brown sample, which is closer to CdSe, shows an increase in band-gap emission and band-gap to defect branching ratio. These results demonstrate that when $\mathrm{Se}$ is the dominant anion, its excitation will result in a large increase in band-gap emission since energy is transferred directly to the emission sites. However, in $\mathrm{CdS}_{\mathrm{x}} \mathrm{Se}_{1-\mathrm{x}}$ systems in which $\mathrm{Se}$ is the non-dominant anion, Se excitation will decrease the optical emission by transferring energy away from luminescence sites and de-excitation will occur through non-radiative paths.

\section{CONCLUSION}

We have used a local probe, XAFS at the $\mathrm{Cd}, \mathrm{S}$, and $\mathrm{Se}$ $K$ and $L_{3,2}$-edges to track the structures and electronic properties of the $\mathrm{CdS}_{\mathrm{x}} \mathrm{Se}_{1-\mathrm{x}}$ solid solution nanostructures. It is found that the structure and bonding are dependent on the $\mathrm{S}$ to Se ratio and display properties that are between that of pure CdS and CdSe. The local environment of the minority anion is similar to that in its pure CdS or CdSe form. The minimal distortion of the local environment in the wurtzite crystal structure upon solid solution formation has been observed by XANES and EXAFS. The CdSSe system favors the wurtzite (B4) crystal structure than the cubic (B3) structure. The use of a tunable $\mathrm{X}$-ray source to examine the optical emission of $\mathrm{CdS}_{\mathrm{x}} \mathrm{Se}_{1-\mathrm{x}}$ by XEOL has probed new deexcitation channels which show a defect emission band not previously seen with a laser source. These new energy pathways are related to the morphology, size, and crystallinity of the nanostructure and provide new insight on the optoelectronic properties of $\mathrm{CdS}_{\mathrm{x}} \mathrm{Se}_{1-\mathrm{x}}$ nanostructure alloys.

\section{ACKNOWLEDGMENTS}

Research was performed at the Canadian Light Source, which is supported by the Natural Sciences and Engineering
Research Council (NSERC) of Canada, the National Research Council Canada, the Canadian Institutes of Health Research, the Province of Saskatchewan, Western Economic Diversification Canada, and the University of Saskatchewan. PNC/XSD facilities at the Advanced Photon Source, and research at these facilities, are supported by the US Department of Energy - Basic Energy Sciences, a Major Resources Support grant from NSERC. Use of the Advanced Photon Source is also supported by the U. S. Department of Energy, Office of Science, Office of Basic Energy Sciences, under Contract No. DE-AC02-06CH11357. Research at the University of Western Ontario is supported by the NSERC, the Canadian Foundation for Innovation, the Ontario Innovation Trust, and the Canada Research Chair program (T.K.S.). Additionally, the assistance of beam-line scientists Robert Gordon, Tom Regier, and Lucia Zuin is gratefully acknowledged.

${ }^{1}$ T. Kyunkendall, P. Ulrich, S. Aloni, and P. Yang, Nature Mater. 6, 951 (2007).

${ }^{2}$ Y. K. Liu, J. A. Zapien, Y. Y. Shan, C. Y. Geng, C. S. Lee, and S. T. Lee, Adv. Mater. 17, 1372 (2005).

${ }^{3}$ A. Pan, H. Yang, R. Liu, R. Yu, B. Zou, and Z. L. Wang, J. Am. Chem. Soc. 127, 15692 (2005).

${ }^{4}$ A. Pan, W. Zhou, E. S. P. Leong, R. Liu, A. H. Chin, B. Zou, and C. Z. Ning, Nano Lett. 9, 784 (2009).

${ }^{5}$ A. Pan, L. Yao, Y. Qin, Y. Yang, D. S. Kim, R. Yu, B. Zou, P. Werner, M. Zaracharias, and U. Gosele, Nano Lett. 8, 3413 (2008).

${ }^{6}$ S. K. Lim, M. J. Tambe, M. M. Brewster, and S. Gradecak, Nano Lett. 8, 1386 (2008).

${ }^{7}$ J. Su, M. Gherasimova, G. Cui, H. Tsukamoto, J. Han, T. Onuma, M. Kurimoto, S. F. Chichibu, and C. Broadbridge, Appl. Phys. Lett. 87, 183108 (2005).

${ }^{8}$ Y. K. Liu, J. A. Zapien, Y. Y. Shan, H. Tang, C. S. Lee, and S. T. Lee, Nanotechnology 18, 365606 (2007).

${ }^{9}$ Y. Liang, L. Zhai, X. Zhao, and D. Xu, J. Phys. Chem. B 109, 7120 (2005).

${ }^{10}$ C. H. Ku, H. H. Chiang, and J. J. Wu, Chem. Phys. Lett. 404, 132 (2005).

${ }^{11}$ L. Chen, H. Falk, P. J. Klar, W. Heimbrodt, F. Brieler, M. Froba, H. A. Krug von Nidda, A. Loidl, Z. Chen, and Y. Oka, Phys. Status Solidi B 229, 31 (2002).

${ }^{12}$ Y. J. Hsu, S. Y. Lu, and Y. F. Lin, Adv. Funct. Mater. 15, 1350 (2005).

${ }^{13}$ A. Pan, R. Liu, M. Sun, and C. Z. Ning, J. Am. Chem. Soc. 131, 9502 (2009).

${ }^{14}$ L. Gundlach and P. Piotrowiak, J. Phys. Chem. C 113, 12162 (2009).

${ }^{15}$ J. A. Zapien, Y. K. Liu, Y. Y. Shan, H. Tang, C. S. Lee, and S. T. Lee, Appl. Phys. Lett. 90, 213114 (2007).

${ }^{16}$ A. Pan, H. Yang, R. Yu, and B. Zou, Nanotechnology 17, 1083 (2006).

${ }^{17}$ R. S. Mane and C. D. Lokhande, Thin Solid Films 304, 56 (1997).

${ }^{18}$ Y. L. Kim, J. H. Jung, K. H. Kim, H. S. Yoon, M. S. Song, S. H. Bae, and Y. Kim, Nanotechnology 20, 095605 (2009).

${ }^{19}$ M. Ali, S. Chattopadhyay, A. Nag, A. Kumar, S. Sapra, S. Chakraborty, and D. D. Sarma, Nanotechnology 18, 075401 (2007).

${ }^{20}$ R. W. G. Wyckoff, Crystal Stuctures, 2nd ed. (John Wiley \& Son, New York, 1963), Vol. 1.

${ }^{21}$ L. Vegard, Z. Phys. 5, 17 (1921).

${ }^{22}$ C. Levelut, A. Ramos, J. Petiau, and M. Robino, Mater. Sci. Eng., B 8, 251 (1991).

${ }^{23}$ P. V. Kmat, J. Phys. Chem. C 112, 18737 (2008).

${ }^{24}$ C. Klingshirn and H. Haug, Phys. Rep. 70, 315 (1981).

${ }^{25}$ P. Lagarde and A.-M. Flank, Chemical Applications of Synchrotron Radiation - Part II: X-ray Applications, edited by T. K. Sham (World Scientific, Singapore, 2002), pp. 629-663.

${ }^{26}$ A. Rogalev and J. Goulon, Chemical Applications of Synchrotron Radiation-Part II: X-ray Applications, edited by T. K. Sham (World Scientific, Singapore, 2002), pp. 707-760.

${ }^{27}$ T. K. Sham, D. T. Jiang, I. Coulthard, J. W. Lorimer, X. H. Feng, K. H. Tan, S. P. Frigo, R. A. Rosenberg, D. C. Houghton, and B. Bryskiewicz, Nature 363, 331 (1993). 
${ }^{28}$ T. K. Sham, S. J. Naftel, P. S. G. Kim, R. Sammynaiken, Y. H. Tang, I. Coulthard, A. Moewes, J. W. Freeland, Y. F. Hu, and S. T. Lee, Phys. Rev. B 70, 045313 (2004).

${ }^{29}$ X. T. Zhou, F. Heigl, M. W. Murphy, T. K. Sham, T. Regier, I. Coulthard, and R. I. R. Blyth, Appl. Phys. Lett. 89, 213109 (2006).

${ }^{30}$ X. T. Zhou, F. Heigl, J. Y. P. Ko, M. W. Murphy, J. G. Zhou, T. Regier, R. I. R. Blyth, and T. K. Sham, Phys. Rev. B 75, 125303 (2007).

${ }^{31}$ R. A. Rosenberg, G. K. Shenoy, F. Heigl, S. T. Lee, P. S. G. Kim, X. T. Zhou, and T. K. Sham, Appl. Phys. Lett. 86, 263115 (2005).

${ }^{32}$ R. A. Rosenberg, G. K. Shenoy, F. Heigl, S. T. Lee, P. S. G. Kim, X. T. Zhou, and T. K. Sham, Appl. Phys. Lett. 87, 253105 (2005).

${ }^{33}$ M. W. Murphy, X. T. Zhou, J. Y. P. Ko, J. G. Zhou, F. Heigl, and T. K. Sham, J. Chem. Phys. 130, 084707 (2009).

${ }^{34}$ R. A. Rosenberg, G. K. Shenoy, X. H. Sun, and T. K. Sham, Appl. Phys. Lett. 89, 243102 (2006)

${ }^{35}$ J. A. Zapien, Y. Jiang, X. M. Meng, W. Chen, F. C. K. Au, Y. Lifshitz, and S. T. Lee, Appl. Phys. Lett. 84, 1189 (2004).

${ }^{36}$ J. P. Perdew and Y. Wang, Phys. Rev. B 45, 13244 (1992).

${ }^{37}$ A. D. Becke and E. R. Johnson, J. Chem. Phys. 124, 221101 (2006); F. Tran and P. Blaha, Phys. Rev. Lett. 102, 226401 (2009); D. Koller, F. Tran, and P. Blaha, Phys. Rev. B 83, 195134 (2011).

${ }^{38}$ P. Blaha and K. Schwarz, J. Phys. F: Met. Phys. 17, 899 (1987).

${ }^{39}$ P. Blaha, K. Schwarz, P. Sorantin, and S. B. Trickey, Comput. Phys. Commun. 59, 399 (1990).

${ }^{40} \mathrm{P}$. Hohenberg and W. Kohn, Phys. Rev. 136, B864 (1964).

${ }^{41}$ W. Kohn and L. J. Sham, Phys. Rev. 140, A1133 (1965).

${ }^{42}$ J. C. Fuggle and J. E. Inglesfield, Unoccupied Electronic States: Fundamentals for XANES, EELS, IPS, and BIS (Springer-Verlag, Berlin Heidelberg, 1992).

${ }^{43}$ A. J. Eroles and A. L. Friedberg, J. Am. Ceram. Soc. 48, 223 (1965).
${ }^{44}$ B. K. Teo and P. A. Lee, J. Am. Chem. Soc. 101, 2815 (1979).

${ }^{45}$ Z. H. Sun, H. Oyanagi, M. Uehara, K. Yamashita, A. Fukano, and H. Maeda, J. Phys: Conf. Ser. 190, 012120 (2009).

${ }^{46}$ X. Zhang, F. Wei, W. Yan, and S. Wei, AIP Conf. Proc. 882, 792 (2007).

${ }^{47}$ D. M. Aruguette, M. A. Marcus, L. S. Li, A. Williamson, S. Fakra, F. Gygi, G. A. Galli, and A. P. Alivisatos, J. Phys. Chem. C 111, 75 (2007).

${ }^{48}$ K. Murakoshi, H. Hosokawa, M. Saitoh, Y. Wada, T. Sakata, H. Mori, M. Satoh, and S. Yanagida, J. Chem. Soc. Faraday Trans. 94, 579 (1998).

${ }^{49}$ Y. M. Yiu, M. W. Murphy, L. Liu, Y. Hu, and T. K. Sham, AIP Conf. Proc. 1590, 26 (2014).

${ }^{50}$ E. Harada, A. Hokura, S. Takada, K. Baba, Y. Terada, I. Nakai, and K. Yazaki, Plant Cell Physiol. 51, 848 (2010).

${ }^{51}$ R. H. Parkman, J. M. Charnock, N. D. Bryan, F. R. Livens, and D. J. Vaughan, Am. Mineral. 84, 407 (1999).

${ }^{52}$ M. C. Martins Alves, O. L. Alves, L. C. Barbosa, A. F. Craievich, A. Ramos, and A. Traverse, J. Phys. IV France 7, C2-1251 (1997).

${ }^{53}$ D. Li, M. Bancroft, M. Kasrai, M. E. Fleet, X. H. Feng, K. H. Tan, and B. X. Yang, J. Phys. Chem. Solids 55, 535 (1994).

${ }^{54}$ P. Zhang, S. J. Naftel, and T. K. Sham, J. Appl. Phys. 90, 2755 (2001).

${ }^{55} \mathrm{D}$. Li, M. Bancroft, M. Kasrai, M. E. Fleet, X. H. Feng, and K. H. Tan, Can. Mineral. 33, 949 (1995).

${ }^{56}$ P. Zhang and T. K. Sham, Phys. Scr. T115, 1019 (2005).

${ }^{57}$ X. T. Zhou, P. S. G. Kim, T. K. Sham, and S. T. Lee, J. Appl. Phys. 98, 024312 (2005).

${ }^{58}$ T. K. Sham, S. J. Naftel, and I. Coulthard, J. Appl. Phys. 79, 7134 (1996).

${ }^{59}$ J. G. Zhou, X. T. Zhou, X. Sun, M. Murphy, F. Heigl, T. K. Sham, and Z. F. Ding, Can. J. Chem. 85, 756 (2007).

${ }^{60}$ R. Hill, J. Phys. C: Solid State Phys. 7, 521 (1974).

${ }^{61}$ See supplementary material at http://dx.doi.org/10.1063/1.4902390 for SEM, EDX spectra, and XEOL spectral fits of CdSSe. 